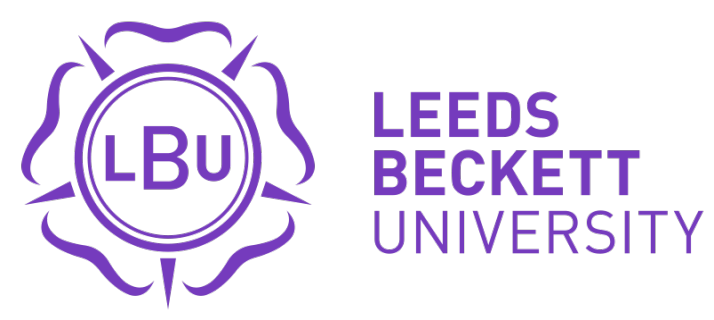

Citation:

Lara-Bercial, S and Solana-Sanchez, A and Solana-Sanchez, D (2016) Athlete and Coach Development in the Sevilla Club de Fútbol Youth Academy: A Values-Based Proposition. International Sport Coaching Journal / ISCJ. ISSN 2328-918X DOI: https://doi.org/10.1123/iscj.2015-0085

Link to Leeds Beckett Repository record:

https://eprints.leedsbeckett.ac.uk/id/eprint/2617/

Document Version:

Article (Accepted Version)

The aim of the Leeds Beckett Repository is to provide open access to our research, as required by funder policies and permitted by publishers and copyright law.

The Leeds Beckett repository holds a wide range of publications, each of which has been checked for copyright and the relevant embargo period has been applied by the Research Services team.

We operate on a standard take-down policy. If you are the author or publisher of an output and you would like it removed from the repository, please contact us and we will investigate on a case-by-case basis.

Each thesis in the repository has been cleared where necessary by the author for third party copyright. If you would like a thesis to be removed from the repository or believe there is an issue with copyright, please contact us on openaccess@leedsbeckett.ac.uk and we will investigate on a case-by-case basis. 


\title{
Athlete and Coach Development in the Sevilla Club de Fútbol Youth Academy:
}

\author{
A Values-based Proposition \\ International Sport Coaching Journal - (accepted for Jan 2016)
}

\author{
Antonio Solana-Sánchez \\ Sevilla CF and Pablo Olavide University, Spain \\ Sergio Lara-Bercial \\ Leeds Beckett University and International Council for Coaching Excellence, UK \\ David Solana-Sánchez \\ Sevilla CF and University of CEU San Pablo, Spain
}

\begin{abstract}
Professional youth football (soccer) academies face a number of challenges related to the contrasting and at times competing nature of their goals. Marrying long-term development of players with success in youth competitions and combining the development of young people as athletes with their growth as human beings are some examples. Professional football clubs and those tasked with leading their academies have to make key decisions as to how these challenges will be addressed. In this paper we argue that those decisions must be made based on a clearly shared philosophy and accompanying set of values. We present some of the key principles governing the work of the Sevilla Club de Fútbol Youth Academy and the rationale behind them. These principles span from developmental, methodological and pedagogical choices to the building of an internal long-term approach to coach development.
\end{abstract}




\title{
Athlete and Coach Development in the Sevilla Club de Fútbol Youth Academy: A Values-based Proposition
}

The life of a child is like a piece of paper. Everyone the child comes across should

\author{
leave an imprint \\ Chinese Proverb
}

Professional youth football (hereon soccer) academies face a number of challenges related to the contrasting and at times competing nature of their goals. Marrying long-term development of players with success in youth competitions and combining the development of young people as athletes with their growth as human beings are some examples. Professional soccer clubs and those tasked with leading their academies have to make key decisions as to how these challenges will be addressed. In this paper we argue that those decisions must be made based on a clearly shared philosophy and accompanying set of values deeply set within the history and culture of the soccer club.

The purpose of this paper is to review the fundamental principles guiding the work of the Sevilla Club de Fútbol (hereon Sevilla CF) Youth Academy. More specifically, in this paper we elaborate on the key philosophical, methodological and pedagogical tenets of its youth player development strategy as well as its unique internal coach development programme. We also describe the rationale behind this approach by highlighting a number of pivotal and sequential reflection moments and subsequent choices which provide a coherent narrative to better understand how the academy operates and why. 
Sevilla CF was founded in 1905 in the city of Sevilla in the Andalucia region of southern Spain. The club places a highly commendable sixth in the historical aggregated classification of the Spanish La Liga and has enjoyed unprecedented success in recent times having won the Europa League in 2006, 2007, 2014 and 2015. For the 2015-2016 season Sevilla CF earned automatic entry in the UEFA Champions League, the most prestigious competition in European football. Sevilla FC manages a budget of around $€ 50 \mathrm{M}$ in relation to player salaries.

The club's youth academy operates a complete structure of teams from Under 8s to Sevilla Atlético, the nursery team for the first squad. All in all 24 teams, over 400 players and over 100 coaching staff work at the Sevilla FC 'José Ramón Cisneros Palacios' City of Sport in the outskirts of town. It is important to understand that the vast majority of academy staff are remunerated part-time and hold unrelated jobs during the day. The academy falls under the technical directorship held by former first team captain Pablo Blanco, and Ramón Rodríguez, a former first team goalkeeper, is the club's Director of Sport

The first author of this paper, Antonio Solana-Sánchez is currently the Director of Coaching Methodology at the academy. His role, in conjunction with the Technical Director, entails the design, communication, implementation and overseeing of the pedagogical and methodological philosophy throughout the academy setting. The second author, Sergio Lara-Bercial, has collaborated with the first author in previous UEFA-led research projects in the area of youth player development. The third author, David Solana-Sánchez is a coach within the academy structure and has also regularly cooperated with the first author on a number of research projects.

\section{Player and Coach Development}

\section{A Rationale in Four Moments of Reflection and Decision-Making}


Multiple factors have an influence on the development and education of young soccer players. Some of them are easily planned for and controllable: i.e. training activities, nutrition, strength and conditioning and technical and tactical development. Other factors, such as the player's environment and lifestyle outside soccer are harder to control. In all of this, however, the figure of the coach has been identified as vital and instrumental to maximise positive outcomes (North, Lara-Bercial, Rongen, \& Morgan, 2015). From this perspective thus, the coach's own process of education and development is paramount. It is therefore necessary to study coaches' practice, analyse it and, if possible, improve it (Abraham, Collins, \& Martindale, 2006; Gilbert, Côté, \& Mallet, 2006; Nash \& Collins, 2006).

At Sevilla CF, we have always understood that in order to develop young athletes' potential, it is necessary to carry out a parallel process of coach development ${ }^{1}$. This is why for the last eight years we have implemented two programmes focused on the improvement of both our players and our coaches. In the remainder of this paper we explain the basic characteristics of both programmes and elaborate on the key moments of reflection and decision-making which have resulted in our current practices.

\section{First Moment of Reflection and Decision-Making}

In a game, the teacher of the game is not the teacher. The teacher is the game itself.

Pierre Parlebas

We see the development of young soccer players as a long-term process. Achieving clarity around what the ultimate objective is appears fundamental to any such

\footnotetext{
1 The authors would like to express their sincere gratitude to Mr Ramón Rodriguez, Sevilla FC Director of Sport, and Mr Pablo Blanco, Sevilla FC Technical Director, not only for their support in writing this paper but for the work and commitment in bringing the contents of the paper to life day to day.
} 
endeavour. At Sevilla CF we started by asking ourselves a key question: What kind of players do we want to produce?

In order to answer this question effectively, it is imperative that we have a clear understanding of the demands of the sport and the challenges players will have to resolve in order to be successful at the highest level. At Sevilla CF we set out to interrogate the sport of soccer in this way so we could clearly define the developmental parameters which would influence the answer to our first question.

Soccer is about resolving, quickly, and in conjunction with a number of teammates relentless waves of unforeseen situations and challenges in either a simultaneous or a successive manner. As a sport, soccer is characterised by the following:

- $\quad$ All actions of the game are determined by the tactical solution which emerges from the interaction between the multiple elements that make up the game (teammates, opposition, the ball, the desired goal and the available space).

- Although this interaction possesses a collective dimension, it is heavily influenced by the individual actions of each player (individual dimension).

- $\quad$ There exists great variability in the space at the players' disposal.

- $\quad$ There are a high number of possible combinations of collective movement and actions, be they simultaneous or successive. This creates a high level of uncertainty with regards to how any situation will play out.

- Given the above described dynamic of the game, player and team effectiveness is thus mediated by the ability to analyse game situations and the decision making capacity of the players. Soccer is cognitively very demanding. Once the parameters of the sport were broadly defined, our next challenge was to clearly determine the type of soccer player we wanted to produce, both from an 
individual and collective standpoint. It was clear in our minds that we wanted to develop 'expert' soccer players, players who have the ability to solve all the unforeseen circumstances and challenges that the game presents.

From this point of view, expert players (a) are perceptually efficient, (b) select information that is most relevant to the current context, (c) reduce attention load directing it to the development of a suitable response, (d) need to use less resources for each information processing instance and (e) execute skills automatically.

From a collective perspective, we needed to develop a model of the game, not a playing system, which served as a vehicle to channel individual performances. We believed that had we based our players' education on one single system (i.e. 1-4-3-3; 14-4-2; 1-4-2-3-1, etc.) we would be restricting coach and player development. The model of the game goes beyond the systems question. It is all about establishing a set of technical-tactical behaviours in the various phases of the game. In this way, we are able to (a) use different playing systems according to the players' age group or the makeup of the different teams every year, (b) allow players to play in different positions until the age of 16-17, and (c) above all, have players who are fully developed physically, technically, tactically, emotionally and socially and not only in one or two of these elements.

For instance, if we always looked for a tall, strong, finisher type of striker, we would be forcing the team to play in a particular way and we would be stopping other talented, yet not tall or strong players from playing in that position. In summary, we followed a line of work that allowed us to develop expert players able to adapt to the needs of the game. That is a model of the game. Our model of the game is based around a number of parameters: 
- Maximum time spent by all players in contact with the ball. This conditions the design of the training tasks and even the way we wish to play the ball from the back in the development phase of the game in match situations (be it from the keeper, from a free kick or a throw-in)

- Analysis of the various zones of the pitch in order to obtain a numerical advantage both offensively and defensively

- Use of key concepts such as compact defensive lines or width and depth on the attack

- $\quad$ Continuous player and ball movement. This involves the consistent creation and occupation of spaces and the relentless search for passing lanes

- $\quad$ Persistence to regain possession immediately after a turnover

- $\quad$ Force the opposition to play through the flanks (outside edges of the field). Thus, it is mandatory to deny inside passing and to keep the defensive lines close together.

\title{
Second Moment of Reflection and Decision-Making
}

\author{
We don't possess that which we don't comprehend. \\ Johan Wolfgan von Goethe
}

This quote by Johan Wolfgan von Goethe has had a great influence on our philosophy and ways of working. It is framed on the wall in the lead author's office and alluded to during meetings with coaches. Having analysed the sport and what players need to be effective and develop their potential, we had to decide the way in which we would approach this task. This presented yet another moment of reflection and a new 
question: Which pedagogical approach would give us the greatest chance to achieve our goal?

Once various methodological proposals were considered (traditional pedagogies vs alternative ones) and after a profound time of introspection, it became clear that the Teaching Games for Understanding model (TGfU) (Bunker \& Thorpe, 1982) was the one closest to what we thought represented best practice in talent development. TGfU is a game-based, learner-centred approach strongly linked to a constructivist view of learning (Griffin \& Patton, 2005).

In agreement with this methodological approach, we believe that successful performance is not built from technical prowess, but from the foundation of a deep knowledge of the game which leads to the adoption and adaptation of technical skills to the tactical and strategic demands of the game or sport.

However, we go beyond this philosophical tenet. We do not believe in a divide between the technical and tactical. Therefore, training must not be focused on the development of one or the other. The game happens as a whole, and as such it must be understood. In every training task, in every exercise, in every match, the phases of the game and the individual and collective behaviours are intertwined and are impossible to dissociate. Players must learn all of this together. For this to happen, the educational setting, instead of differentiating between technical and tactical development or attack and defence, should strive to articulate them into an all-inclusive technical-tacticaldefensive-offensive education.

\section{Third Moment of Reflection and Decision-Making}

Experience does not depend on the number of things we have seen, but on the number of things we have reflected upon. 
José María Pereda

Having chosen this particular pedagogy of coaching (i.e., TGfU), the next question we addressed was: Which methodological coaching principles are suitable to implement this pedagogy and realise our ultimate goal?

The answers to each of the questions posed in succession, consistently led us to another question and in this way we progressively moved from a much more theoretical and philosophical level of thinking to considerably more specific ones rooted in the practice of coaching. At this point we needed to commit to our choices and elaborate the foundational stones of our methodology in agreement with decisions taken in the previous steps. We created eight fundamental principles that underpin our methodology.

1. The ball, the player, opposition, teammates and space are the fundamental elements of training sessions and they must be present in the vast majority of exercises. Therefore, the ball must be present throughout the session. Obvious as it sounds, this meant a clean break from traditional physical conditioning training. One of the key decisions made early on was to bring the Strength and Conditioning Department under the supervision and care of the Department of Methodology. In this way, we stopped doing conditioning out of the context of the game. For example, from the Under 18 squad down, there is no endurancetype work such as continuous running or interval training. The development of this element of fitness is linked to the regular training tasks.

2. Learning is cyclical with content revisited regularly. During the season there are no discrete blocks of set content over a period of time. In contrast, all elements of the mode of the game are developed in unison all of the time. See figure 1 below for a sample weekly plan. 
3. The planning of the training cycles is done from the model of the game and its principles and sub-principles. Seasons, blocks and sessions are planned with the objective of progressively developing the integrated capabilities required of the players to fulfil the club's model of the game (i.e. being able to expertly execute the principles and sub-principles of the model). The isolated mastery of technical and tactical skills unrelated to the model is not sought. The pieces must fit into the overall model.

4. Training exercises must provide players with the what, the how, the when and the why. The mindless running of technical and tactical drills is forbidden. All training exercises must develop the skill, but most importantly the understanding of how, when and why it is performed. This approach also allows for players to develop 'their own way' as long as it is functional within the model.

5. Elements such as perception, peripheral vision, decision-making, attention, concentration, etc, are present from the beginning of the session. In sum, we aim for a high cognitive load and demand every day.

6. Quality and intensity must be maintained over time and in the long-term. Sessions are carefully designed and analysed to ensure that maximum levels of physical and cognitive quality and intensity are kept at all times. Cognitive and physical loads are closely monitored throughout the season.

7. Attacking and defending drills do not exist separate from each other. All training tasks simulate actions of the game which will later occur in real matches.

8. Training tasks or activities are carried out with varying levels of complexity modifying key parameters like space (large, medium, small), the rules/conditions of the task leading to more or less cognitive demands, and the 
number of players (equal versus numerical advantage/disadvantage). Figure 2 offers a graphic representation of these parameters.

\section{Fourth Moment of Reflection and Decision-Making}

The good coach is able to persuade the players without hypnotising them.

Adapted from Spanish philosopher Fernando Savater

All the decisions made up to this point were leading us towards the need for coaches who had vast knowledge of the development of the game. We needed coaches who would be able to appropriately select those scenarios or game situations which were most conducive to the development of expert players. The idea of best practice cast a long shadow over us again, and forced us to answer the following question: What kind of coaches are the most appropriate to fulfil this role?

We had to determine if our existing coaches had the right makeup to put into practice this methodological revolution and display these working practices. Most importantly, we needed to know if they would be willing to commit to the change or if they would remain in their comfort zone.

We needed coaches who could master different areas of teaching to guarantee learning. Teaching and learning are two sides of the same coin. The coach and the player must be perfectly synchronised. We start from the belief that the coach is a central figure in the development of the player. The coach is the link between the child and the sport. The level of pedagogical responsibility is very high and this demands a lot from the coach from both a technical and a human development point of view.

We divided coach competencies into three dimensions:

Technical and psycho-pedagogical dimension: competencies related to 
knowledge of the sport (technical, tactical, physical, planning, etc) and also psycho-pedagogical competencies (task design, feedback, skill acquisition, correct the behaviour not the person; positive reinforcement; observation, analysis and evaluation skills, training space management, etc.). Management dimension: knowledge and personal aptitude to manage all aspects of training. For instance, group organisation, timetabling, travel arrangements. In sum, their ability to pre-empt and solve problems, not to create them.

Personal-emotional-affective dimension: personal skills which facilitate the building of positive relationships with others and increase their motivation. Leadership, motivational and social skills are examples. Likewise, personal commitment, robust values and beliefs and sound ethics are of utmost importance.

A fundamental dilemma emerged from this analysis. Two possibilities had to be weighed up. On the one hand, we could go out and find coaches who did not have the club at heart, who did not know the idiosyncrasies of the institution nor its sociocultural context in which our players develop. Moreover, coaches who would very likely use our club as a spring board to other clubs and who did not deeply care about developing young talent but more about their own professional progression. The positive side of this approach would be the capacity to implement our process of methodological innovation in an easier and faster manner. On the other hand, we could think more mid and long-term and develop our existing coaches who know the club well, its philosophy, and its context. These local coaches, 'carry the club in their heart' and really suffer when a player brought up at the club does not make it to the first team or does not have a professional career. The disadvantage to this approach is that it 
would take us longer to implement our revamp of the player development methodology. After a period of reflection we opted for the latter option; we decided to invest in the development of our own coaches.

\section{An In-House, On-the-job Continuous Coach Development Programme}

In order to do support our existing coaches' efforts to grow into the new demands of the job, we had to develop a continuous development programme. It is important to realise that education and development must be continuous (lifelong), flexible (to suit the learner), relentless (every day) and reciprocal (from educator to learner and vice versa). In this sense, learning should be occurring all the time for all involved in the process.

In order for the coach development programme to succeed, we implemented our program in the following phases.

\section{Phase 1: Development of Collaborative Awareness.}

Coaches needed to understand that everything we did had one common goal - to develop expert players for the first team. Without their cooperation this would not be possible. They needed to see me (the lead author) as being on their side, not as their manager or boss or passing judgement on them. We all had to pull in the same direction, under supervision, yet in the same boat. For this to happen, it was not sufficient to hold regular meetings in an office. It was necessary to spend time getting to know the coaches, being close to them, building a relationship, motivating them, regular phone chats, informal discussion on the touchline or even chats outside working hours. In sum, my attitude and behaviours were aimed at getting them to buy into the project and to own it. This role must be played constantly. The message must be continuously reinforced.

Phase 2: Introduction of the New Methodology. 
During the first few months, my role focused on the removal of pedagogical behaviours that we felt were inappropriate for our project. Our strategy revolved around analysing and correcting training sessions, getting the coach to realise that we were starting to use the TGfU methodology and moving away from the more traditional ways of coaching. This process was a long one. It lasted two years. Initially, we focused on the design of the exercises and the flow of the sessions. These were concrete, immediate and tangible things for coaches. Defining which types of activities were in line with the new methodology and which ones needed to be progressively discarded and forgotten was a key step. To this effect we established regular developmental meetings in small groups where we explained the new methodology.

These were followed up by individual meetings to exchange ideas. All along, we always tried to convince and persuade rather than impose. We strived to convince the coaches that the new way would help them plan and make their job easier. They were offered help in relation to session development, task design and graphic representation. It was important to start with tasks and exercises that were already known to them, trying to minimise information overload. They were given basic information about the aims of certain tasks without going into principles and sub-principles of the game or the model of the game. Too much information could have led to coaches rebelling against the programme. We were conscious that if they started putting together appropriate tasks and exercises with our feedback, we would be hitting aspects related to the model of the game, its principles and the phases of play.

The next step was to broaden our area of influence and to start having an impact on how they planned their training week. Again, we used the same persuasive approach. Little by little, we continued to expand our area of influence up to a point where we got them to make the links between different tasks/exercises, sessions, weeks, planning 
cycles and the model of the game, its principles and sub-principles and more complex methodological areas.

In order to facilitate this for the coach, and following the 'principle of simplicity', we created a system that links different colours with different types of training weeks. Being true to our philosophy, we work on all the principles of the game horizontally (i.e. we integrate them rather than isolate them and expect that over the period of 8 to 10 years players spend at the academy they reach high levels of proficiency in all of them). However, each colour refers to a more specific area of the model of the game. For instance, blue denotes a week where we emphasise ball and player movement, yet not forgetting all the other elements. An orange week focuses more on positional work (i.e. actions of the game from specific player positions and scenarios). And finally, a red week brings together all the phases of the game and we provide lots of match time against local teams or between our own teams (Figure 3).

We regularly conducted coach observations during training sessions and matches followed by one to one meetings to assess psycho-pedagogical behaviours such as excessive periods of verbal communication, lack of time on motor-development tasks, and reduced individual feedback. This process was repeated constantly all along the way.

To summarise, it could be said that our coach development programme revolves around the following key principles:

1. A fundamental need to raise coaches' awareness around the common goals of the club and the importance of collaborative and joint-up work to achieve them.

2. Supporting coaches to develop a pedagogical approach which builds players' knowledge and understanding and increases their buy-in and ownership of the training programme. 
3. Provide coaches clear, simple and concrete information especially in the early stages of development (i.e. avoid excessive philosophical paraphernalia or jargon during the initial implementation phase to then little by little start introducing deeper questions and stimulate higher level thinking).

4. Use a positive approach to reinforce and reassure those coaches who are buying into the new methodology. Slowly but surely, those who are not prepared to 'recycle' will isolate themselves and leave the project; and most importantly, ensure that coaches undergoing this transformative process see the senior staff as resources to be used on demand rather than solely performance managers.

\section{Impact of the Approach}

The impact of our choices can be measured both from the perspective of the players and the coaches. The main goal of the academy is to develop expert players who are able to play for the first team. From this standpoint, and from a modest yet objective perspective, it is our belief that the Sevilla CF Youth Academy fulfils its role admirably well and has become a beacon of good practice in Spanish and European soccer. Over the last 10 years, more than 40 players developed through the academy system have made their debut with the first team and are enjoying very successful careers with Sevilla CF and beyond. In fact, an indirect measure of success, albeit a very important one for the club's board of directors, is the amount of revenue generated from sales of players to other clubs. Between 2012 and 2015 Sevilla CF generated $€ 50 M$ from the sale of home-grown talent, fourth highest among European soccer clubs (CIES Football Observatory, 2015). In some cases, these players have become international icons like Sergio Ramos (Sevilla CF, Real Madrid CF and Spain), Jesús Navas (Sevilla CF, Manchester City and Spain), José Antonio Reyes (Sevilla CF, Arsenal, Atlético Madrid $\mathrm{CF}$ and Spain) and Antonio Marchena (Sevilla CF, Valencia CF, Villarreal CF and 
Spain).

In addition to this, another measure of the success of the academy is the number of players who represent Spain at youth European and World Championships. Over the last five years alone, 25 Sevilla CF players have had the privilege of wearing 'la roja', the distinctive red shirt of the national team, in European and World Championships from Under $15 \mathrm{~s}$ to Under $21 \mathrm{~s}$.

Finally, and to honour one of our most beloved sayings at the academy ('Educate while Competing and Compete while Educating'), the Sevilla CF academy squads have enjoyed a fair amount of success in regional and national championships in the last five years. All in all, our teams have recently won four national championships and a multitude of regional championships from under-10s to under-19s. We believe Sevilla CF is living proof that winning early and developing players is compatible if underpinned by the right philosophy and methods.

With regards to impact on the coaches, we focus on three key indicators to evaluate our programme. The first one relates to the observable daily behaviours we see in training and competition. One set of behaviours relates to how well players are able to cope with the demands of soccer within our model of the game (i.e., how well do the teams perform against the specific criteria of our model). For the most part, our teams play with a very distinct identity and, in the main, clearly exhibit the traits of the Sevilla model. The other set of behaviours relates to how well coaches are able to interpret the model and develop sessions and programmes which use our selected pedagogy and methodology. Both the Director of Methodology and the Technical Director spend a large part of their time observing training sessions and matches and again, for the most part, what we see is consistent with our player development approach.

Our second coach performance indicator concerns the level and type of 
communication between coaching staff and the directors. There are constant casual, semi-formal and formal meetings between coaches and directors. The most positive sign is that while in the early days, directors had to chase coaches for planning and review meetings, now coaches see these meetings as opportunities to make sure they are delivering on message and as stepping stones to further learning and development. Formal review meetings have become less necessary and in turn coaches informally and actively seek out the directors' counsel and advice and a community of practice seems to have emerged.

Finally, perhaps the performance indicator we are most proud of is the fact that coach turnover is very low. Sevilla CF academy coaches, despite their part-time status and long and demanding working hours, choose to remain with the club. We believe that a combination of their love for the club of their heart and the appreciation of the investment the club makes into their own development compensates for any downsides.

\section{Conclusion}

Running an elite youth soccer development academy within a top professional club is not easy. However, when the philosophies of the club and academy directors are aligned, a cohesive and coherent approach can be implemented. There are no shortcuts and unless there is total alignment between the philosophy and values of all involved, misunderstandings and disagreements will get the best of the project. Within this complex landscape, the innovative role of the Academy Director of Methodology is a fundamental piece of the puzzle. The Director of Methodology not only helps design and develop the roadmap to success, but more importantly is the conduit between the theories of academia, the boardroom and the practices of coaches on the ground. The coach is thus recognised as a central figure in the development of elite soccer players. Moreover, careful, sustained and directed investment to internally and externally 
support the development of a modern, expert and interconnected coaching workforce is paramount. At Sevilla CF we take pride in developing local talent by local coaches. 


\section{References}

Abraham, A., Collins, D. \& Martindale, R. (2006). The coaching schematic: Validation expert coach consensus. Journal of Sports Sciences, 24 (6), 549-564.

Bunker, D. \& Thorpe, R. (1982). A model for the teaching of games in secondary schools. Bulletin of Physical Education, 18 (1), 5-8.

CIES Football Observatory. (2015). Most profitable youth academies. Big-5 Weekly Post, 102.

Gilbert, W. D., Côté, J. \& Mallet, C. (2006). Developmental paths and activities of successful sport coaches. International Journal of Sport Science \& Coaching, 1 (1), 69-76.

Griffin, L. \& Patton, K. (2005). Two decades of Teaching Games for Understanding: looking at the past, pre- sent, and future. In L. Griffin \& J. I. Butler (Eds.), Teaching games for understanding. Theory, research, and practice (pp. 1-17). Champaign, IL: Human Kinetics.

Nash, C. \& Collins, D. (2006). Tacit knowledge in expert coaching: Science or art? Quest, 58, 465-477.

North, J., Lara-Bercial, S., Morgan, G., \& Rongen, F. (2015). The identification of good practice principles to inform player development and coaching in European youth football. Report commissioned by UEFA's Research Grant Programme 2013-2014. 


\section{BLUE WEEK}

\begin{tabular}{|c|c|c|c|c|c|c|}
\hline Mon & Tue & Wed & Thu & $\mathrm{Fri}$ & Sot & Sun \\
\hline $\begin{array}{l}\text { Technical } \\
\text { Development } 45^{\prime}\end{array}$ & Rest & $\begin{array}{l}\text { Strength } 8 \text {. } \\
\text { Conditioning / } \\
\text { Video in } 2 \text { groups } \\
30\end{array}$ & $\begin{array}{l}\text { Technical } \\
\text { Development } \\
45^{\prime}\end{array}$ & $\begin{array}{l}\text { Set pieces } \\
10^{\circ}\end{array}$ & Rest & League Match \\
\hline $\begin{array}{l}\text { Ball and Player } \\
\text { Movement (non- } \\
\text { position specific) } \\
2 \sigma^{\prime}\end{array}$ & & $\begin{array}{l}\text { Initiating \&. } \\
\text { Creating from the } \\
\text { Back (inc. } \\
\text { goalkesper \&. } \\
\text { specific positions] } \\
30\end{array}$ & $\begin{array}{l}\text { Finishing } \\
\text { Combined with } \\
\text { Position } \\
\text { Specific } \\
\text { Strength } \\
20\end{array}$ & $\begin{array}{l}\text { Finishing } \\
\text { Combined with } \\
\text { Position Specific } \\
\text { Speed } \\
20\end{array}$ & & \\
\hline $\begin{array}{l}\text { Initiating \&. } \\
\text { Creating from the } \\
\text { Back (inc. } \\
\text { goalkesper \&. } \\
\text { specific positions } \\
\text { 130 }\end{array}$ & & $\begin{array}{l}\text { Mid-Third Creation } \\
\text { (position specific) } \\
40^{\prime}\end{array}$ & $\begin{array}{l}\text { Ball \&. Player } \\
\text { Movement } \\
\text { (non-position } \\
\text { specific) } \\
25^{\prime}\end{array}$ & $\begin{array}{l}\text { Conditioned } \\
\text { Games (all game } \\
\text { phases) } \\
4 O^{\prime}\end{array}$ & & \\
\hline $\begin{array}{l}\text { Conditioned } \\
\text { Games (all three } \\
\text { phases) } \\
15-25^{\prime}\end{array}$ & & $\begin{array}{l}\text { Conditioned } \\
\text { Games (all game } \\
\text { phases) } \\
2 \sigma^{\prime}\end{array}$ & $\begin{array}{l}\text { Conditioned } \\
\text { Games (all } \\
\text { game phases) } \\
30^{\prime}\end{array}$ & $\begin{array}{l}\text { Unconditioned } \\
\text { Match } \\
20^{\prime}\end{array}$ & & \\
\hline
\end{tabular}

Figure 1. Sample training week for an Under 18 squad. 


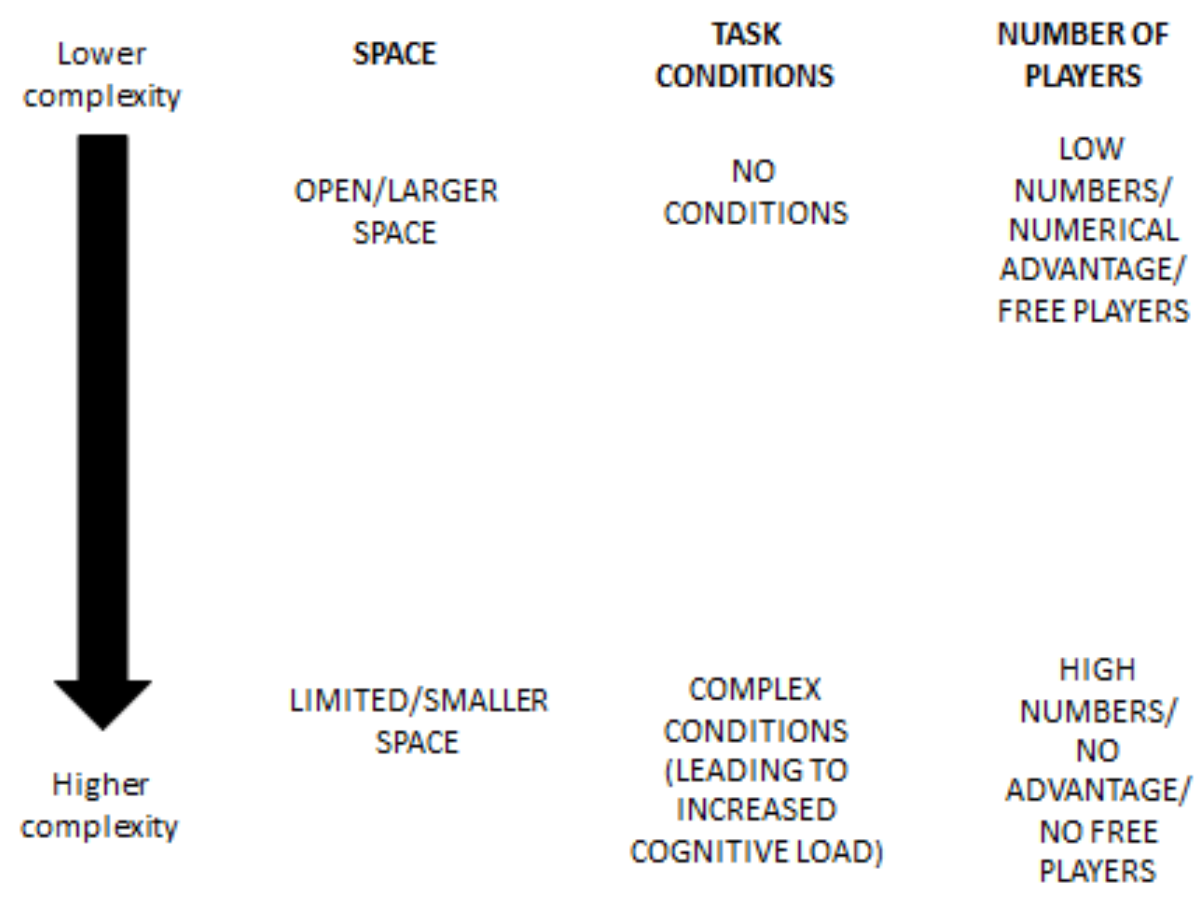

Figure 2. Parameters used for task design. 

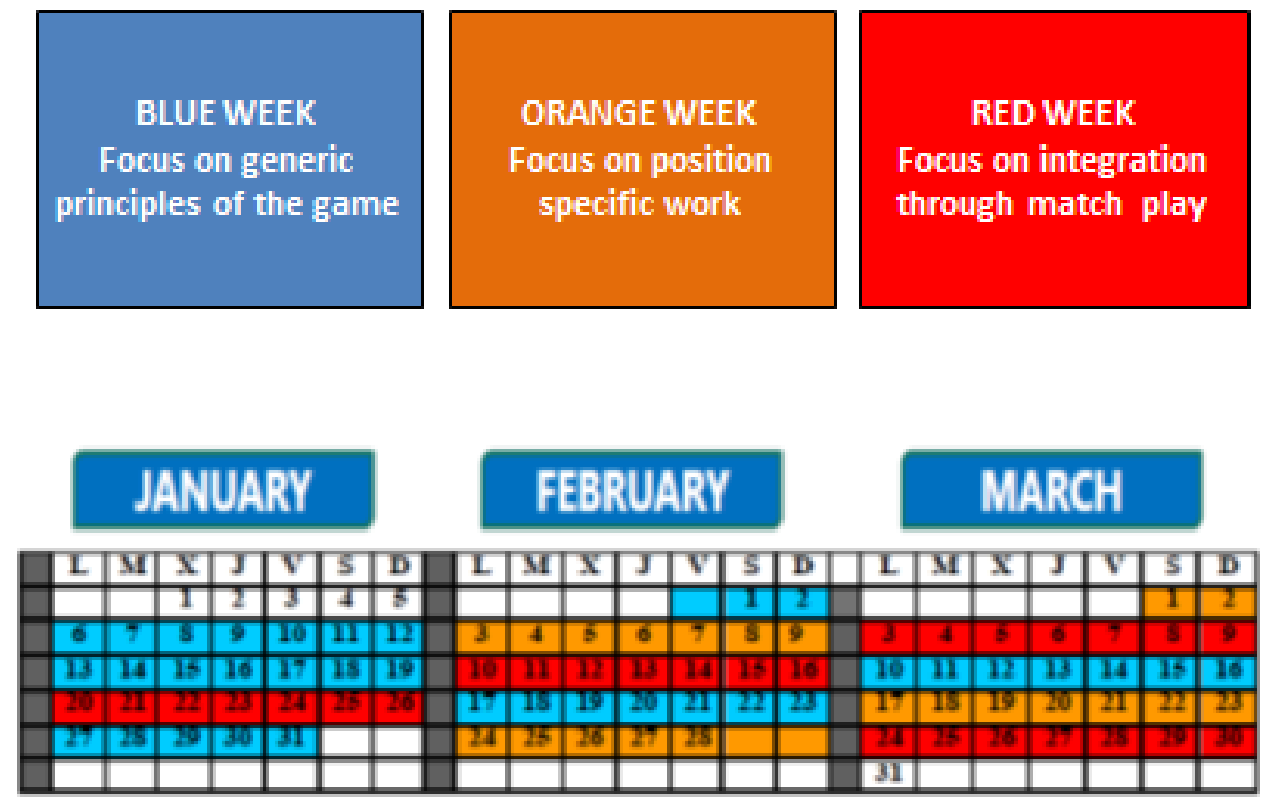

Figure 3. Sample 3-month planning block depicting weekly colour-coded development priorities. 